\title{
Kansei design customization based on personality modelling
}

\begin{abstract}
Product designers are obliged to meet the userôs desires; both implicit and explicit ones. Identifying the implicit needs is a complicated task. The methods of Kansei Engineering (KE) have aided in this process by using analysis of human emotions. KE starts by detecting the feelings and emotions towards a developing product and ends in giving product designs that satisfy users. However, can a single design satisfy all users? How can customization be done without losing any Kansei? Knowing the different needs and types of emotional expression between human personalities, this paper explores how modifications in the KE Framework can capture these differences and apply them to the final designs. The results of this process will be a set of customized designs for groups of similar personalities, knowing each design has captured the different interests of those groups.
\end{abstract}

Keyword: Kansei engineering; Kansei design; Kansei words; Personality type; Enneagram; MBTI 